\title{
Hyperhomocysteinemia in Alzheimer's Disease: The Hen and the Egg?
}

\author{
Melinda Farkas ${ }^{\mathrm{a}}$, Salla Keskitalo ${ }^{\mathrm{a}}$, Desiree E.C. Smith ${ }^{\mathrm{b}}$, Nadja Bain ${ }^{\mathrm{a}}$, Alexander Semmler ${ }^{\mathrm{a}}$, \\ Benjamin Ineichen ${ }^{\mathrm{a}}$, Yvo Smulders ${ }^{\mathrm{b}}$, Henk Blom ${ }^{\mathrm{b}}$, Luka Kulic ${ }^{\mathrm{a}, \mathrm{c}, 1}$ and Michael Linnebank ${ }^{\mathrm{a}, 1, *}$ \\ ${ }^{a}$ Department of Neurology, University Hospital Zurich, Zurich, Switzerland \\ ${ }^{\mathrm{b}}$ Department of Clinical Chemistry, Metabolic Unit, VU University Medical Center, Amsterdam, The Netherlands \\ ${ }^{\mathrm{c}}$ Department of Psychiatry, University of Zurich, Zurich, Switzerland
}

Accepted 2 October 2012

\begin{abstract}
Hyperhomocysteinemia is associated with Alzheimer's disease (AD). The causality of this association is controversial. In this study we tested the effect of a hyperhomocysteinemia-inducing diet in the ArcA $\beta$ transgenic AD mouse model. At 14 months of age, the hyperhomocysteinemia-inducing diet yielded higher plasma homocysteine levels in ArcA $\beta$ mice compared with wild-type mice. Levels of plasma 5-methyltetrahydrofolate (5-MTHF) in 14-month-old mice on hyperhomocysteinemiainducing diet were lower in the transgenic than in the wild-type mice. The folate derivate 5-MTHF serves as cofactor in homocysteine metabolism. Oxidative stress, which occurs in the course of disease in the ArcA $\beta$ mice, consumes 5-MTHF. Thus, the transgenic mice may plausibly be more vulnerable to 5-MTHF-depleting effects of hyperhomocysteinemia and more vulnerable to hyperhomocysteinemia-inducing diet. This argues that AD pathology predisposes to hyperhomocysteinemia, i.e., as a facultative consequence of AD. However, we also observed that dietary-induced folate reduction and homocysteine increase was associated with an increase of plasma (young animals) and brain (older animals) amyloid- $\beta$ concentrations. This suggests that the hyperhomocysteinemia-inducing diet worsened pathology in the transgenic mice. In conclusion, this data may argue that folate reduction and hyperhomocysteinemia may contribute to neurodegeneration and may also be triggered by neurodegenerative processes, i.e., represent both a cause and a consequence of neurodegeneration. Such a vicious cycle may be breakable by dietary or supplementation strategies increasing the availability of 5-MTHF.
\end{abstract}

Keywords: Alzheimer's disease, diet, folic acid, homocysteine, hyperhomocysteinemia, mice, transgenic, vitamin B6, vitamin B12

\section{INTRODUCTION}

Sporadic Alzheimer's disease (AD) is the most common form of dementias. Higher age, female gender, and presence of the apolipoprotein E4 allele have been identified as risk factors. In addition, hyperhomocysteinemia is independently associated with AD [1]. Factors like higher age, male gender, renal dysfunction, genetic variants, high methionine uptake via

\footnotetext{
${ }^{1}$ These authors contributed equally.

*Correspondence to: Michael Linnebank, Department of Neurology, University Hospital Zurich, Frauenklinikstrasse 26, 8091 Zurich, Switzerland. Tel.: +41 44255 1111; Fax: +41 44255 4507; E-mail: michael.linnebank@usz.ch.
}

protein-rich food, and deficiencies of folate, vitamin B12, and vitamin B6 are linked to hyperhomocysteinemia [2]. The nature of the relationship between hyperhomocysteinemia and AD is controversial [3-5].

Homocysteine is a toxic intermediate of methionine metabolism. It is either irreversibly metabolized by the vitamin B6-dependent transsulfuration pathway or is recycled to methionine by the folate- and vitamin B12-dependent remethylation pathway (Fig. 1). Methionine can be activated to S-adenosylmethionine (SAM), which serves as universal methyl-group donor, e.g., for DNA, RNA, and protein methylation reactions. SAM is thereby converted to S-adenosylhomocysteine (SAH), which is further hydrolyzed to homocysteine in a reversible reaction. Although elevated plasma 


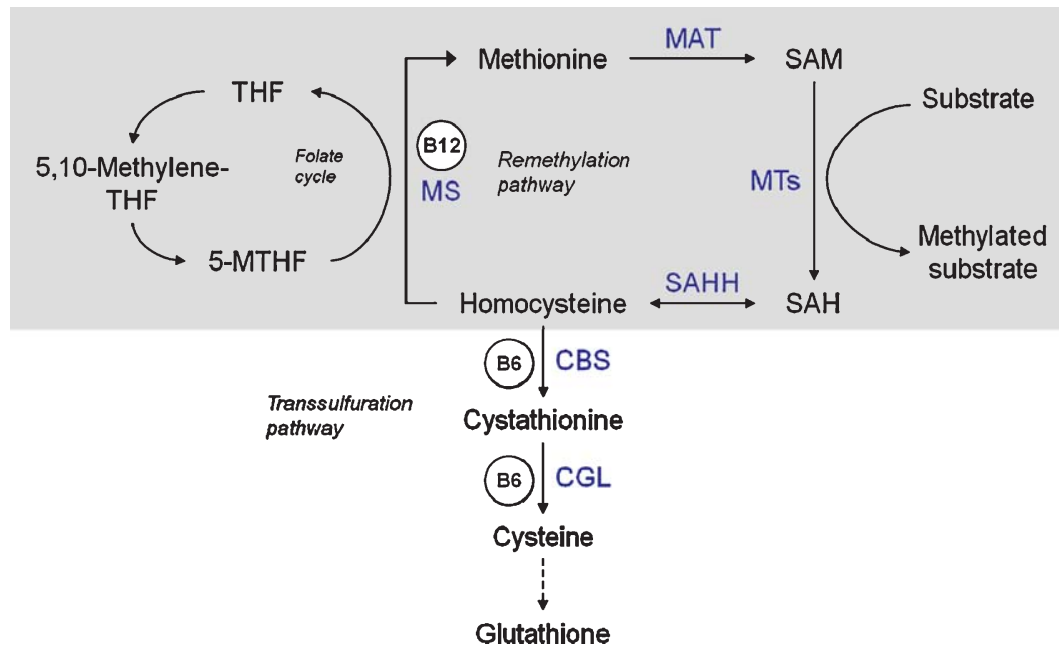

Fig. 1. The two pathways of homocysteine metabolism. In the remethylation pathway, the methyl group from 5-methyl-tetrahydrofolate (5-MTHF) is transferred to homocysteine by the vitamin B12-dependent enzyme methionine synthase (MS), producing methionine and tetrahydrofolate (THF). Methionine is activated to S-adenosylmethionine (SAM) by methionine adenosyltransferase (MAT) transferring adenosine from ATP. SAM acts as methyl group donor for a diversity of methylation reactions catalyzed by methyltransferases (MTs) producing S-adenosylhomocysteine (SAH), which is reversibly hydrolyzed to homocysteine by SAH hydrolase (SAHH). In the transsulfuration pathway, homocysteine is irreversibly degraded to cystathionine by the vitamin B6-dependent enzyme cystathionine- $\beta$ synthase (CBS) and then further catalyzed to cysteine, a precursor of glutathione, by the vitamin B6-dependent enzyme $\gamma$-cystathionase (CGL).

homocysteine levels have consistently been reported as an independent risk factor for $\mathrm{AD}[1,6,7]$ and predict cognitive decline in $\mathrm{AD}$ patients [8], several interventional trials have not observed beneficial effects of homocysteine-lowering strategies in $\mathrm{AD}[3$, 9-11]. However, the recent VITACOG trial showed a highly significant reduction in brain atrophy as an effect of homocysteine-lowering vitamins in individuals with mild cognitive impairment [12]. In AD patients, high serum homocysteine levels are often accompanied by low serum folate levels $[6,13]$. Low folate levels may be an additional independent AD risk factor [14, 15] and may independently correlate with cognitive decline in AD patients $[8,16]$. Cerebrospinal fluid (CSF) folate levels were decreased in $\mathrm{AD}$ patients in some [17-19], but not all studies $[20,21]$. CSF and brain SAM levels, which depend on the availability of folate (Fig. 1), are decreased in $\mathrm{AD}[20,22,23]$. Whether hyperhomocysteinemia is an independent causal AD risk factor or occurs as secondary epiphenomenon of neurodegeneration, is an important unanswered question. To test the hypothesis that changes of homocysteine metabolism occur during the natural course of neurodegeneration, we analyzed plasma homocysteine and folate levels and their association with brain and plasma $A \beta_{1-40}$ and $A \beta_{1-42}$ fractions in the $\operatorname{Arc} A \beta$ mouse model.

\section{MATERIALS AND METHODS}

The ArcA $\beta$ mouse strain overexpresses human A $\beta P P$ containing the Swedish double mutation (Swe; K670 N; M671 L) and the Arctic mutation (E693 G) [24]. ArcA $\beta$ mice exhibit extracellular amyloid- $\beta$ (A $\beta$ ) plaque deposition starting at 7 months of age followed by massive $A \beta$ plaque formation and cerebral $\mathrm{A} \beta$ angiopathy between 9 and 15 months. These biochemical hallmarks are accompanied by progressive cognitive impairment of spatial memory starting at 6 months.

In this study, $40 \mathrm{ArcA} \beta$ mice (18 female; 22 male) and 51 wild-type littermates ( 33 female; 18 male) were fed either normal diet $(3 \mathrm{~g} / \mathrm{kg}$ methionine; $2 \mathrm{mg} / \mathrm{kg}$ folic acid) or methionine-rich diet $(20 \mathrm{~g} / \mathrm{kg}$ methionine, inducing hyperhomocysteinemia without folate depletion) from the age of three months until sacrificed at the age of 6 or 14 months, respectively. In-cage behavior and body weight were monitored. Total plasma homocysteine and 5-MTHF were measured after cardiac puncture in terminal anesthesia; other folate fractions were below the threshold of measurement $[25,26]$. Brains were extracted and snap frozen. For the analysis of the $A \beta$ fractions, the brains were homogenized in liquid nitrogen, lysed in precooled 2\% SDS buffer $\mathrm{pH}=8.0$ (2\% SDS, $100 \mathrm{mM}$ TrisBase, $150 \mathrm{mM} \mathrm{NaCl}, 1 \mathrm{x}$ protease and phosphatase 
inhibitor solutions (Roche)) and centrifuged for $30 \mathrm{~min}$ at $100,000 \times g$ at $8^{\circ} \mathrm{C}$. Supernatants (=SDS-soluble brain $\mathrm{A} \beta$ fraction) were stored at $-80^{\circ} \mathrm{C}$ until further measurements. Pellets were dissolved in $70 \%$ formic acid by ultra-sonication and centrifuged for $30 \mathrm{~min}$ at $100,000 \times g$ at $4^{\circ} \mathrm{C}$. Supernatants (= SDS-insoluble brain $A \beta$ fraction) were transferred to low-bind Eppendorf tubes and lyophilized. Pellets were resolved in $2 \%$ SDS buffer $\mathrm{pH}=8.0$ and stored at $-80^{\circ} \mathrm{C}$ until further measurements.

Brain and plasma $A \beta_{1-40}$ and $A \beta_{1-42}$ fractions were measured with the Meso Scale Discovery System Multiplexed A $\beta$ Ultra-Sensitive Assays (Meso Scale Diagnostics, LLC, Gaithersburg MD, USA). Plasma homocysteine levels were not normally distributed and were therefore transformed to a logarithmic scale for statistical analysis. Metabolite levels were analyzed by Pearson's correlation and by multivariate-ANOVA with the variables age, diet, genotype, and gender followed by multivariate-ANOVA of the age and diet subgroups with the variables genotype and gender. Animal experiments were approved by the Federal veterinary office and conducted according to the Swiss Law for Animal Protection.
A

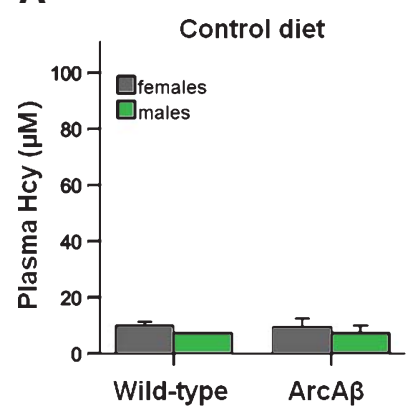

Methionine rich diet

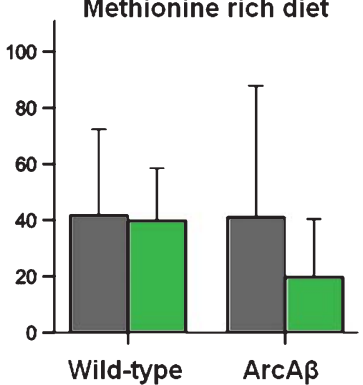

14-month-old mice
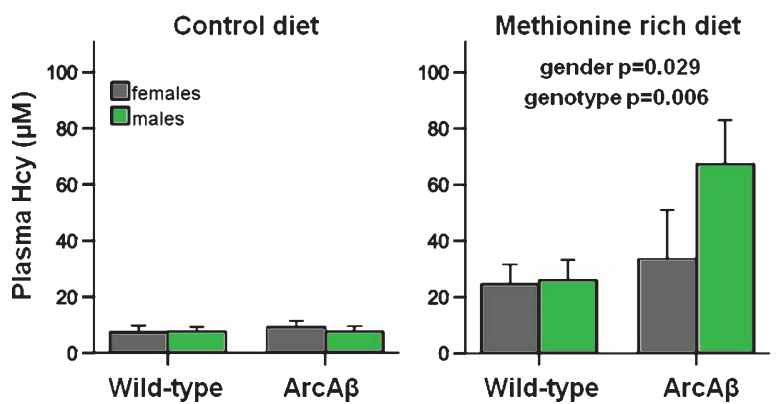

\section{RESULTS}

In-cage behavior, food intake, and body weight were not associated with genotype or diet. As expected, the methionine-rich diet led to increased plasma homocysteine levels in both the 6- and the 14-month-old animals (log plasma homocysteine at 6 months $p=0.022, \log$ plasma homocysteine at 14 months $p<0.001$; Fig. 2A). Plasma homocysteine levels did not differ between age groups, independent from the diet (Fig. 2A). However, the 14-month-old $\operatorname{ArcA} \beta$ mice on methionine-rich diet had higher plasma homocysteine levels than their wild-type littermates on the same diet (log plasma homocysteine $p=0.006$, Fig. 2A).

To gather further information on the reasons for stronger methionine-induced hyperhomocysteinemia in transgenic mice at a progressed stage of pathology, we next measured the concentrations of the main biological folate derivative, 5-MTHF. As expected, the methionine-rich diet group showed reduced 5-MTHF levels (6 months $p<0.001,14$ months $p<0.001$; Fig. 2B). However, at 14-months of age, 5-MTHF levels negatively correlated with homocysteine levels in the $\operatorname{ArcA} \beta$ mice only $(r=-0.861 ; p=0.001)$.
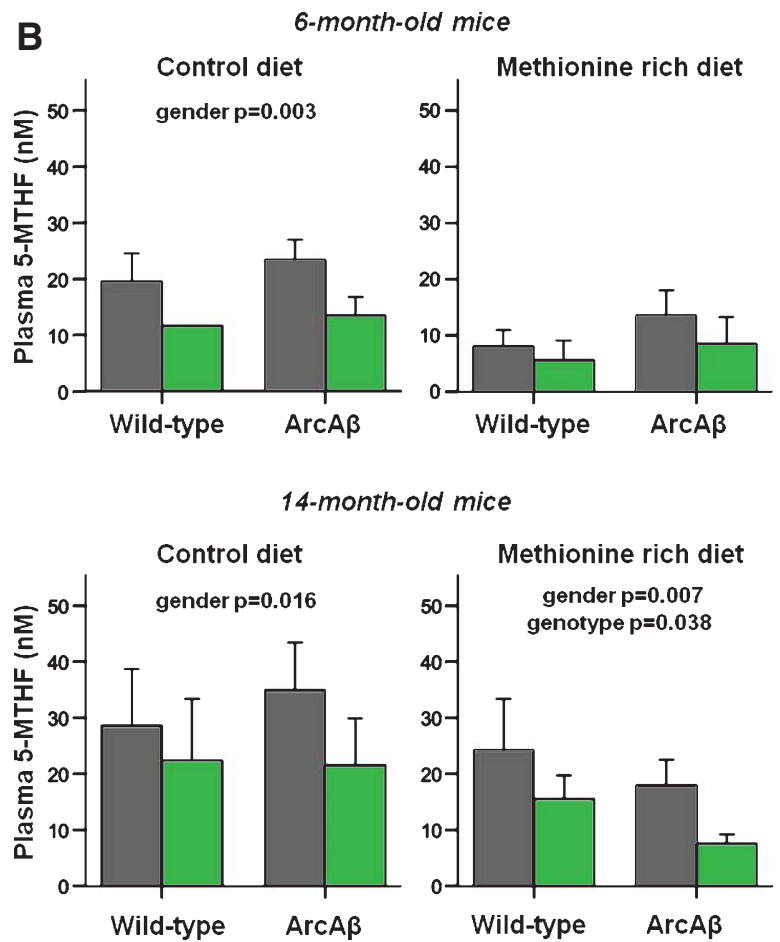

Fig. 2. Metabolite concentrations of A) plasma homocysteine and B) plasma 5-MTHF of wild-type and ArcA $\beta$ mice on either control diet or methionine rich diet at the ages of 6 months and 14 months. Values represent mean \pm standard deviation. Statistically significant difference between the two genotypes or genders is indicated (analysis of variance over all groups). 

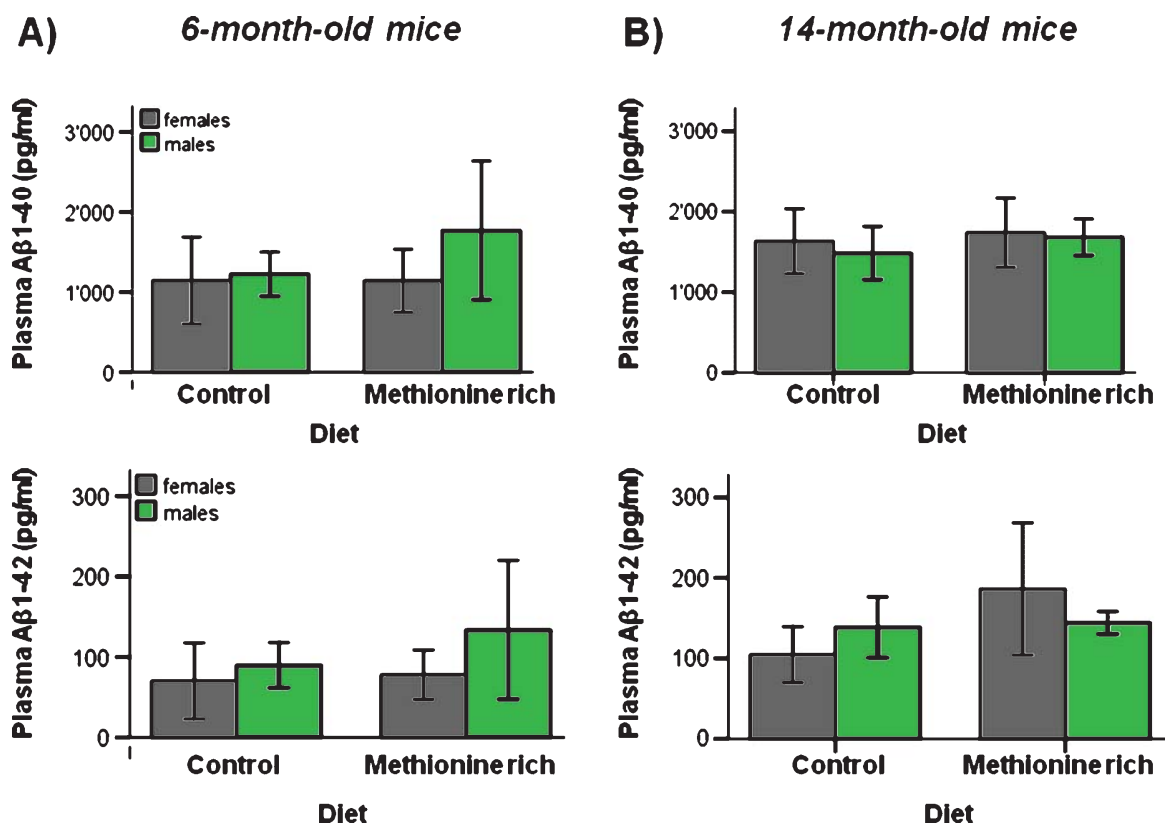

Fig. 3. Concentrations of plasma $A \beta_{1-40}$ and $A \beta_{1-42}$ in $A r c A \beta$ mice on either control diet or methionine rich diet at the ages of $A$ ) 6 months and B) 14 months. Values represent mean \pm standard deviation. Statistically significant difference between the two genotypes or genders is indicated (analysis of variance over all groups).

Further, 5-MTHF was lower in males than in females $(p<0.001)$, but this was not associated with homocysteine plasma levels (Fig. 2A, B).

\section{A $\beta$ levels}

As expected, plasma $A \beta_{1-40}$ and $A \beta_{1-42}$ levels were higher in the 14-month-old ArcA $\beta$ mice $(1619 \pm 350$ $\mathrm{pg} / \mathrm{mL}$ and $146 \pm 56 \mathrm{pg} / \mathrm{mL})$ than in 6-month-old ArcA $\beta$ mice $(1288 \pm 468 \mathrm{pg} / \mathrm{mL}$ and $92 \pm 44 \mathrm{pg} / \mathrm{mL}$; $p=0.033$ and $p=0.006$, respectively; Fig. 3). In addition, in the 6-month-old animals, $A \beta_{1-42}$ levels inversely correlated with plasma 5-MTHF levels $(r=-0.521, p=0.027$, Fig. 4$)$, which was not significant in the progressed, i.e., 14-month-old, animals $(r=-0.164, p=0.465)$.

Levels of both the SDS-soluble and the SDSinsoluble brain $A \beta_{1-40}$ and $A \beta_{1-42}$ fractions were below the detection limits in wild-type mice and in 6month-old ArcA $\beta$ mice. In the 14-month-old ArcA $\beta$ mice, SDS-insoluble brain $A \beta_{1-40}$ and $A \beta_{1-42}$ were higher in animals on methionine-rich diet, which was significant for $A \beta_{1-40}$ in the female mice only $(F=11.715$; $p=0.027$; Fig. 5). Further explorative analyses revealed that, in these animals, SDS-insoluble brain $\mathrm{A} \beta_{1-40}(p=0.058$ for trend) and SDS-insoluble brain $A \beta_{1-42}$ levels negatively correlated with plasma

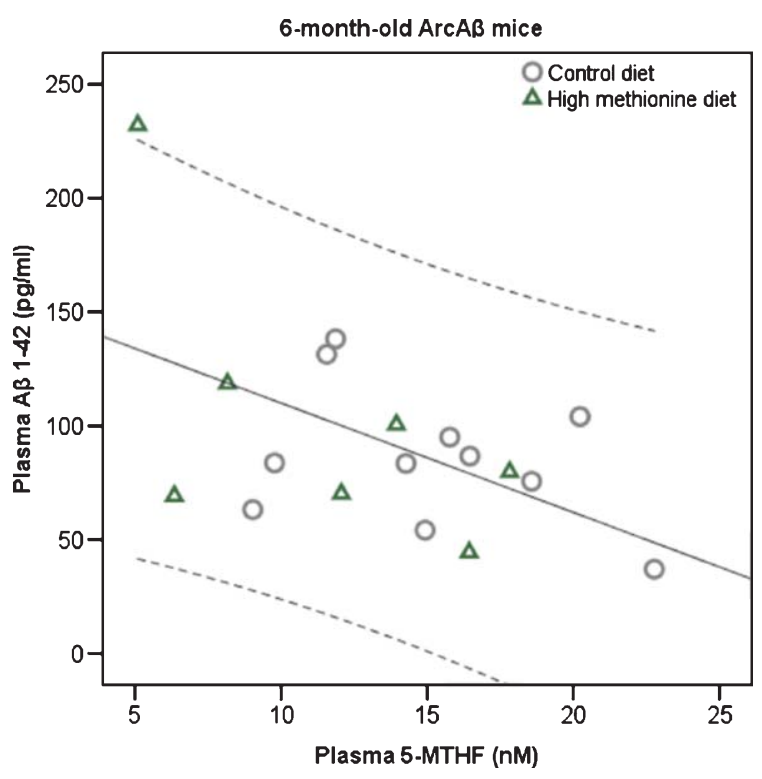

Fig. 4. Correlation between plasma 5-MTHF and plasma $A \beta_{1-42}$ in 6-month-old $\operatorname{Arc} \mathrm{A} \beta$ mice on either control diet (circles) or high methionine diet (triangles). Pearson correlation $r=-0.527$, $p=0.027, n=18$.

5-MTHF levels ( $r=-0.905, p=0.013$; Fig. 6) and with plasma homocysteine levels for trend $(r=0.808$, $p=0.051)$. 

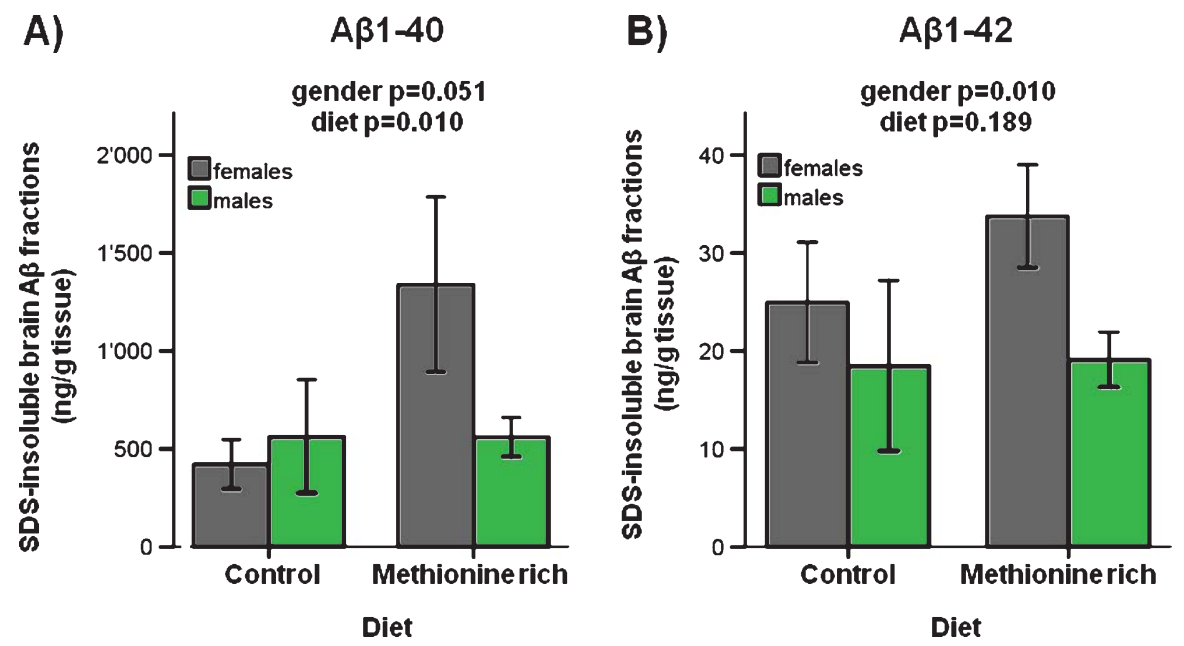

Fig. 5. Concentrations of SDS-insoluble brain $A$ ) $A \beta_{1-40}$ and $B$ ) $A \beta_{1-42}$ in 14-months-old ArcA $\beta$ mice on either control diet or methionine rich diet. Values represent mean \pm standard deviation. Statistically significant difference between the two genotypes or genders is indicated (analysis of variance over all groups).

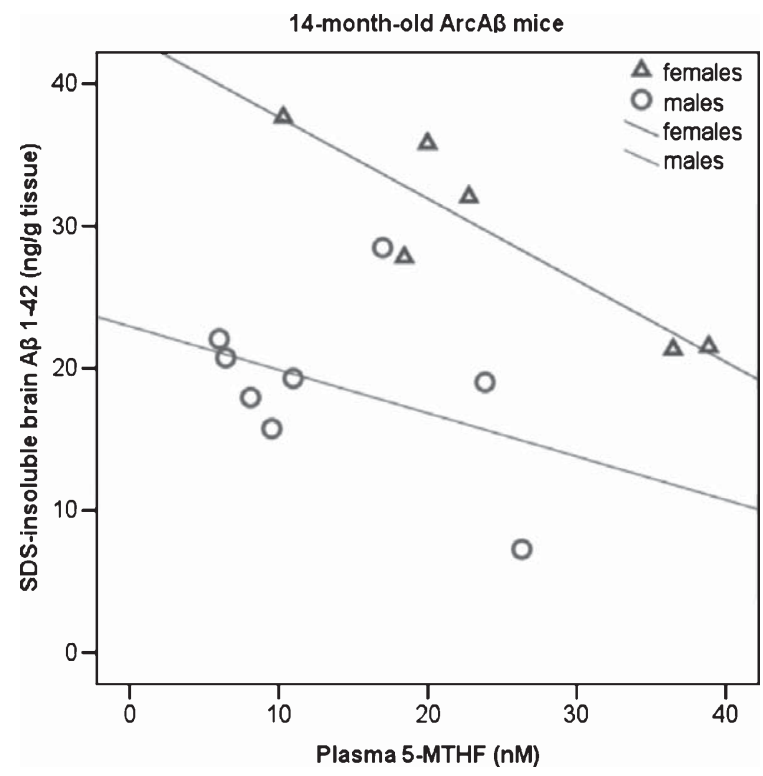

Fig. 6. Correlation between plasma 5-MTHF and SDS-insoluble brain $A \beta_{1-42}$ levels in 14-month-old $\operatorname{ArcA} \beta$ mice of both diet groups. Pearson correlation was calculated for females (triangles; $r=-0.905, p=0.013, n=6$ ) and males (circles; $r=-0.404$, $p=0.321, n=8)$.

\section{DISCUSSION}

Hyperhomocysteinemia is a risk factor for AD. In animal models, hyperhomocysteinemia induced by folate depletion promotes $\mathrm{AD}$ pathology [4, 34]. However, in patients low serum folate levels were observed as risk factor for cognitive decline independent from hyperhomocysteinemia questioning the role of homocysteine in folate-induced hyperhomocysteinemia in AD models $[14,15]$. We analyzed homocysteine and the major biological folate derivative, 5-MTHF, in an AD mouse model, both in the natural course and under nutritional conditions inducing hyperhomocysteinemia without manipulating diet folate concentrations. As major result, we observed a reduction of plasma 5-MTHF levels and an increase of plasma homocysteine levels in higher aged transgenic animals with progressed pathology in comparison to age-matched littermates. However, these differences between transgenic and control mice were only observable in the group on hyperhomocysteinemia-inducing diet, whereas in the normal diet group, no differences between genotypes were observed. We also found negative correlations of brain (progressed pathology) and plasma A $\beta$ levels (early pathology) with 5-MTHF and, for trend, with homocysteine (progressed pathology) levels suggesting that a possible direct or indirect interaction between folate and homocysteine metabolism with $A \beta$ may not be restricted to the central nervous system, but may take place on a systemic level.

Importantly, oxidative stress and inflammation can deplete 5-MTHF, thereby increasing plasma homocysteine levels $[27,28]$. A $\beta$ induces oxidative stress and inflammation in the brain $[29,30]$. Thus, Hoffman proposed that hyperhomocysteinemia is a consequence of folate depletion caused by oxidative stress [31]. In our study, under nutritional conditions elevating homocysteine plasma levels without folate depletion, mice with progressed neurodegeneration exhibited 
stronger hyperhomocysteinemia associated with lower 5-MTHF levels in comparison to wild-type littermates. This offers room to speculate on co-acting effects of neurodegeneration and hyperhomocysteinemia leading to 5-MTHF reduction. In the course of a vicious cycle, reduced 5-MTHF increases homocysteine, which itself promotes oxidative stress, 5-MTHF reduction, and elevated $A \beta$ levels [32]. In line with our findings, another A $\beta P P$-transgenic mouse model at a progressed stage had higher plasma homocysteine levels compared to the wild-type animals [33], whereas in mice at early phenotypic stage or on standard laboratory chow [34], no association between genotype and plasma homocysteine levels were observed [35]. In accordance to our animal data, men have higher plasma homocysteine levels than women [13]. However, we could only speculate whether there are specific differences explaining that some associations were restricted to one gender in our study, which also might be explained by chance regarding the decreased number of animals in gender subgroup analyses.

Reduction of 5-MTHF levels leads to decreased remethylation of homocysteine to the methyl group donor SAM and higher levels of the SAM antagonist $\mathrm{SAH}$, with the consequence of a reduced SAM/SAHratio (Fig. 1). In addition to the above mentioned general aspects concerning 5-MTHF, homocysteine, oxidative stress, and neurodegeneration, such effects on the SAM/SAH-ratio affect site-specific methylation patterns of genes involved in $A \beta$ generation in cell culture and in animal studies [4, 36, 37], e.g., leading to an increased expression of presenilin 1 and increased brain $\mathrm{A} \beta$ levels in both wild-type mice and A $\beta P P$ transgenic mouse models $[4,38,39]$. Such increase of $A \beta$ can be prevented by dietary SAM supplementation $[4,38,40,41]$ underlining the relevance of methylation processes and of 5-MTHF as co-factor for SAM-synthesis in AD pathophysiology. The data of our study suggests that the relationship between low plasma folate levels, hyperhomocysteinemia, and $\mathrm{AD}$ is not unidirectional. In the progressed transgenic mice, hyperhomocysteinemia-inducing diet led to lower folate and higher homocysteine blood levels compared to wild-type littermates suggesting that, on the one hand, the diet had a decisive influence on folate reduction and, on the other hand, that the transgenic genotype is associated with increased vulnerability to folate reduction under such nutritional conditions. The higher increase of homocysteine observed in the progressed transgenic mice on hyperhomocysteinemia-inducing diet might well have been secondarily to the lower folate levels when compared to wild-type mice with same age and on the same diet. Speculatively, the combination of oxidative stress in neurodegeneration and of the specific diet might best explain the folate reduction and the pronunciation of hyperhomocysteinemia in the progressed transgenic mice on hyperhomocysteinemia-inducing diet. As folate levels negatively correlated with $A \beta$, the current experiments suggest that such changes of folate levels may be pathophysiologically relevant. We conclude that the transgenic mice are more vulnerable to develop folate depletion and hyperhomocysteinemia under respective dietary conditions and that such biochemical changes contribute to AD-like pathology. Thus, changes of folate and homocysteine metabolism may be both contributor to and consequence of neurodegeneration. This may be a vicious cycle breakable by homocysteinelowering vitamins as suggested by the VITACOG trial [12].

\section{DISCLOSURE STATEMENT}

Authors' disclosures available online (http://www.jalz.com/disclosures/view.php?id=1538).

\section{REFERENCES}

[1] Seshadri S, Beiser A, Selhub J, Jacques PF, Rosenberg IH, D'Agostino RB, Wilson PW, Wolf PA (2002) Plasma homocysteine as a risk factor for dementia and Alzheimer's disease. $N$ Engl J Med 346, 476-483.

[2] Mudd SH, Levy HL, Skovby F (1995) Disorders of transsulfuration, McGraw-Hill, New York.

[3] Zhuo JM, Wang H, Pratico D (2011) Is hyperhomocysteinemia an Alzheimer's disease (AD) risk factor, an AD marker, or neither? Trends Pharmacol Sci 32, 562-571.

[4] Fuso A, Nicolia V, Cavallaro RA, Ricceri L, D'Anselmi F, Coluccia P, Calamandrei G, Scarpa S (2008) Bvitamin deprivation induces hyperhomocysteinemia and brain S-adenosylhomocysteine, depletes brain Sadenosylmethionine, and enhances PS1 and BACE expression and amyloid-beta deposition in mice. Mol Cell Neurosci 37, 731-746.

[5] Linnebank M, Linnebank A, Jeub M, Klockgether T, Wullner U, Kolsch H, Heun R, Koch HG, Suormala T, Fowler B (2004) Lack of genetic dispositions to hyperhomocysteinemia in Alzheimer disease. Am J Med Genet A 131, 101-102.

[6] Clarke R, Smith AD, Jobst KA, Refsum H, Sutton L, Ueland PM (1998) Folate, vitamin B12, and serum total homocysteine levels in confirmed Alzheimer disease. Arch Neurol 55, 14491455 .

[7] Linnebank M, Popp J, Smulders Y, Smith D, Semmler A, Farkas M, Kulic L, Cvetanovska G, Blom H, Stoffel-Wagner B, Kolsch H, Weller M, Jessen F (2010) Sadenosylmethionine is decreased in the cerebrospinal fluid of patients with Alzheimer's disease. Neurodegener Dis 7, 373-378.

[8] Kim JM, Kim SW, Shin IS, Yang SJ, Park WY, Kim SJ, Shin HY, Yoon JS (2008) Folate, vitamin b(12), and homocysteine 
as risk factors for cognitive decline in the elderly. Psychiatry Investig 5, 36-40.

[9] McMahon JA, Green TJ, Skeaff CM, Knight RG, Mann JI, Williams SM (2006) A controlled trial of homocysteine lowering and cognitive performance. $N$ Engl J Med 354, 2764 2772.

[10] Dangour AD, Whitehouse PJ, Rafferty K, Mitchell SA, Smith L, Hawkesworth S, Vellas B (2010) B-vitamins and fatty acids in the prevention and treatment of Alzheimer's disease and dementia: A systematic review. J Alzheimers Dis 22, 205-224.

[11] Malouf M, Grimley EJ (2008) Folic acid with or without vitamin B12 for the prevention and treatment of healthy elderly and demented people. Cochrane Database Syst Rev 4. CD004514.

[12] Smith AD, Smith SM, de Jager CA, Whitbread P, Johnston C, Agacinski G, Oulhaj A, Bradley KM, Jacoby R, Refsum H (2010) Homocysteine-lowering by B vitamins slows the rate of accelerated brain atrophy in mild cognitive impairment: A randomized controlled trial. PLoS One 5, e12244.

[13] Haan MN, Miller JW, Aiello AE, Whitmer RA, Jagust WJ, Mungas DM, Allen LH, Green R (2007) Homocysteine, B vitamins, and the incidence of dementia and cognitive impairment: Results from the Sacramento Area Latino Study on Aging. Am J Clin Nutr 85, 511-517.

[14] Quadri P, Fragiacomo C, Pezzati R, Zanda E, Forloni G, Tettamanti M, Lucca U (2004) Homocysteine, folate, and vitamin B-12 in mild cognitive impairment, Alzheimer disease, and vascular dementia. Am J Clin Nutr 80, 114-122.

[15] Ravaglia G, Forti P, Maioli F, Martelli M, Servadei L, Brunetti N, Porcellini E, Licastro F (2005) Homocysteine and folate as risk factors for dementia and Alzheimer disease. Am J Clin Nutr 82, 636-643.

[16] Kado DM, Karlamangla AS, Huang MH, Troen A, Rowe JW, Selhub J, Seeman TE (2005) Homocysteine versus the vitamins folate, B6, and B12 as predictors of cognitive function and decline in older high-functioning adults: MacArthur Studies of Successful Aging. Am J Med 118, 161167.

[17] Hagnelius NO, Wahlund LO, Nilsson TK (2008) CSF/serum folate gradient: Physiology and determinants with special reference to dementia. Dement Geriatr Cogn Disord 25, 516523.

[18] Serot JM, Christmann D, Dubost T, Bene MC, Faure GC (2001) CSF-folate levels are decreased in late-onset AD patients. J Neural Transm 108, 93-99.

[19] Smach MA, Jacob N, Golmard JL, Charfeddine B, Lammouchi T, Ben Othman L, Dridi H, Bennamou S, Limem K (2011) Folate and homocysteine in the cerebrospinal fluid of patients with Alzheimer's disease or dementia: A case control study. Eur Neurol 65, 270-278.

[20] Mulder C, Schoonenboom NS, Jansen EE, Verhoeven NM, van Kamp GJ, Jakobs C, Scheltens P (2005) The transmethylation cycle in the brain of Alzheimer patients. Neurosci Lett 386, 69-71.

[21] Popp J, Lewczuk P, Linnebank M, Cvetanovska G, Smulders Y, Kolsch H, Frommann I, Kornhuber J, Maier W, Jessen F (2009) Homocysteine metabolism and cerebrospinal fluid markers for Alzheimer's disease. J Alzheimers Dis 18, 819828.

[22] Bottiglieri T, Godfrey P, Flynn T, Carney MW, Toone BK, Reynolds EH (1990) Cerebrospinal fluid Sadenosylmethionine in depression and dementia: Effects of treatment with parenteral and oral S-adenosylmethionine. $J$ Neurol Neurosurg Psychiatry 53, 1096-1098.
[23] Morrison LD, Smith DD, Kish SJ (1996) Brain Sadenosylmethionine levels are severely decreased in Alzheimer's disease. J Neurochem 67, 1328-1331.

[24] Knobloch M, Konietzko U, Krebs DC, Nitsch RM (2007) Intracellular Abeta and cognitive deficits precede betaamyloid deposition in transgenic arcAbeta mice. Neurobiol Aging 28, 1297-1306.

[25] Ubbink JB, Hayward Vermaak WJ, Bissbort S (1991) Rapid high-performance liquid chromatographic assay for total homocysteine levels in human serum. J Chromatogr 565, 441-446.

[26] Smith DE, Kok RM, Teerlink T, Jakobs C, Smulders YM (2006) Quantitative determination of erythrocyte folate vitamer distribution by liquid chromatography-tandem mass spectrometry. Clin Chem Lab Med 44, 450-459.

[27] Widner B, Fuchs D, Leblhuber F, Sperner-Unterweger B (2001) Does disturbed homocysteine and folate metabolism in depression result from enhanced oxidative stress? J Neurol Neurosurg Psychiatry 70, 419.

[28] Fuchs D, Jaeger M, Widner B, Wirleitner B, Artner-Dworzak $\mathrm{E}$, Leblhuber F (2001) Is hyperhomocysteinemia due to the oxidative depletion of folate rather than to insufficient dietary intake? Clin Chem Lab Med 39, 691-694.

[29] Butterfield DA (2002) Amyloid beta-peptide (1-42)-induced oxidative stress and neurotoxicity: Implications for neurodegeneration in Alzheimer's disease brain. A review. Free Radic Res 36, 1307-1313.

[30] Butterfield DA, Castegna A, Lauderback CM, Drake J (2002) Evidence that amyloid beta-peptide-induced lipid peroxidation and its sequelae in Alzheimer's disease brain contribute to neuronal death. Neurobiol Aging 23, 655-664.

[31] Hoffman M (2011) Hypothesis: Hyperhomocysteinemia is an indicator of oxidant stress. Med Hypotheses 77, 10881093.

[32] Perna AF, Ingrosso D, De Santo NG (2003) Homocysteine and oxidative stress. Amino Acids 25, 409-417.

[33] Bernardo A, McCord M, Troen AM, Allison JD, McDonald MP (2007) Impaired spatial memory in APP-overexpressing mice on a homocysteinemia-inducing diet. Neurobiol Aging 28, 1195-1205.

[34] Santiard-Baron D, Aupetit J, Janel N (2005) Plasma homocysteine levels are not increased in murine models of Alzheimer's disease. Neurosci Res 53, 447-449.

[35] Kruman II, Kumaravel TS, Lohani A, Pedersen WA, Cutler RG, Kruman Y, Haughey N, Lee J, Evans M, Mattson MP (2002) Folic acid deficiency and homocysteine impair DNA repair in hippocampal neurons and sensitize them to amyloid toxicity in experimental models of Alzheimer's disease. J Neurosci 22, 1752-1762.

[36] Scarpa S, Fuso A, D'Anselmi F, Cavallaro RA (2003) Presenilin 1 gene silencing by S-adenosylmethionine: A treatment for Alzheimer disease? FEBS Lett 541, 145-148.

[37] Fuso A, Cavallaro RA, Nicolia V, Scarpa S (2012) PSEN1 promoter demethylation in hyperhomocysteinemic TgCRND8 mice is the culprit, not the consequence. Curr Alzheimer Res 9, 527-535.

[38] Chan A, Shea TB (2007) Folate deprivation increases presenilin expression, gamma-secretase activity, and Abeta levels in murine brain: Potentiation by ApoE deficiency and alleviation by dietary S-adenosyl methionine. J Neurochem $\mathbf{1 0 2}$, 753-760.

[39] Zhuo JM, Pratico D (2010) Acceleration of brain amyloidosis in an Alzheimer's disease mouse model by a folate, vitamin B6 and B12-deficient diet. Exp Gerontol 45, 195-201. 
[40] Fuso A, Nicolia V, Ricceri L, Cavallaro RA, Isopi E, Mangia F, Fiorenza MT, Scarpa S (2012) S-adenosylmethionine reduces the progress of the Alzheimer-like features induced by Bvitamin deficiency in mice. Neurobiol Aging 33, 1482.e1-e16.
[41] Zhuo JM, Pratico D (2010) Normalization of hyperhomocysteinemia improves cognitive deficits and ameliorates brain amyloidosis of a transgenic mouse model of Alzheimer's disease. FASEB J 24, 3895-3902. 